\title{
Unmanned aerial vehicle observations of water surface elevation and bathymetry in the cenotes and lagoons of the Yucatan Peninsula, Mexico
}

Bandini, Filippo; Lopez-Tamayo, Alejandro; Merediz-Alonso, Gonzalo; Olesen, Daniel Haugård; Jakobsen, Jakob; Wang, Sheng; Garcia, Monica; Bauer-Gottwein, Peter

Published in:

Hydrogeology Journal

Link to article, DOI:

10.1007/s10040-018-1755-9

Publication date:

2018

Document Version

Peer reviewed version

Link back to DTU Orbit

Citation (APA):

Bandini, F., Lopez-Tamayo, A., Merediz-Alonso, G., Olesen, D. H., Jakobsen, J., Wang, S., Garcia, M., \& BauerGottwein, P. (2018). Unmanned aerial vehicle observations of water surface elevation and bathymetry in the cenotes and lagoons of the Yucatan Peninsula, Mexico. Hydrogeology Journal, 26(7), 2213-2228. https://doi.org/10.1007/s10040-018-1755-9

\section{General rights}

Copyright and moral rights for the publications made accessible in the public portal are retained by the authors and/or other copyright owners and it is a condition of accessing publications that users recognise and abide by the legal requirements associated with these rights.

- Users may download and print one copy of any publication from the public portal for the purpose of private study or research.

- You may not further distribute the material or use it for any profit-making activity or commercial gain

- You may freely distribute the URL identifying the publication in the public portal 
2 NOTE: published in Hydrogeology Journal

3 https://link.springer.com/article/10.1007\%2Fs10040-018-

$4 \quad \underline{\mathbf{1 7 5 5}-9}$

6 Unmanned aerial vehicle observations of water surface

7 elevation and bathymetry in the cenotes and lagoons of the

8 Yucatan Peninsula, Mexico

9 Filippo Bandini ${ }^{1 *}$, Alejandro Lopez-Tamayo ${ }^{3}$, Gonzalo Merediz-Alonso ${ }^{3}$, Daniel Olesen ${ }^{2}$,

10 Jakob Jakobsen ${ }^{2}$, Sheng Wang ${ }^{1}$, Monica Garcia ${ }^{1}$, Peter Bauer-Gottwein ${ }^{1}$

${ }^{1}$ Department of Environmental Engineering, Technical University of Denmark, Kgs. Lyngby, 2800, Denmark

${ }^{2}$ National Space Institute, Technical University of Denmark, Kgs. Lyngby, 2800, Denmark

${ }^{3}$ Amigos de Sian Ka’an, Calle Fuego No. 2, Manzana 10 SM 4, Cancún, Quintana Roo, 77500, México

*Contact author Filippo Bandini (fban@env.dtu.dk) 
Observations of water surface elevation (WSE) and bathymetry of the lagoons and cenotes of the Yucatán Peninsula (YP) in southeast Mexico are of hydrogeological interest. Observations of WSE (orthometric water height above mean sea level (amsl)) are required to inform hydrological models, to estimate hydraulic gradients and groundwater flow directions. Measurements of bathymetry and water depth (elevation of the water surface above the bed of the water body) improve current knowledge on how lagoons and cenotes connect through the complicated submerged cave systems and the diffuse flow in the rock matrix. A novel approach is described that uses unmanned aerial vehicles (UAVs) to monitor WSE and bathymetry of the inland water bodies on the YP. UAV-borne WSE observations were retrieved using a radar and a global navigation satellite system onboard a multi-copter platform. Water depth was measured using a tethered floating sonar controlled by the UAV. This sonar provides depth measurements also in deep and turbid water. Bathymetry (wet-bed elevation amsl) can be computed by subtracting water depth from WSE. Accuracy of the WSE measurements is better than 5-7 cm and accuracy of the water depth measurements is estimated to be $\sim 3.8 \%$ of the actual water depth. The technology provided accurate measurements of WSE and bathymetry in both wetlands (lagoons) and cenotes. UAV-borne technology is shown to be a more flexible and lower cost alternative to manned aircrafts. UAVs allow monitoring of remote areas located in the jungle of the YP, which are difficult to access by human operators.

Keywords: Mexico, karst, groundwater/surface-water relations, cenote.

\section{Introduction}

The Yucatán Peninsula (YP) in southeast Mexico is a region of high environmental value, hosting one of the world’s largest and most spectacular karst aquifers. Merediz-Alonso (2007) reported the need for new scientific datatypes to identify and advocate appropriate management decisions. Groundwater on the YP has an incommensurable value as it sustains biodiversity and supports numerous ecosystems (Bauer-Gottwein et al. 2011). Around the world, groundwater and surface water can be generally viewed as one continuous water resource, but on the YP the high degree of interaction between groundwater and surface water is probably more evident than anywhere else (e.g. Schiller et al., 2017). Generally karst aquifers are characterised by landforms caused by chemical dissolution of the limestone rock, such as sinkholes (closed depressions, tens of $\mathrm{m}$ in diameter), karst fields (called polje, large depressions with a flat floor, several $\mathrm{km}^{2}$ or more), and karren (also called lapies, fissures and runnels on the surface, tens of cm wide) (Monroe 1970). However, the Chicxulub 
Impact Crater (Sharpton et al. 1992, 1993), discovered by Hildebrand et al. (1991, 1995), played a key role in defining the distinctive structural features of the YP. The footprint of the Chicxulub impact is believed to have caused major fracturing in the limestone bedrock and caused the high density of sinkholes (locally known as cenotes). Because of the Chicxulub impact, cenotes are especially dense along a semi-circular line named the ring of cenotes (Perry et al. 1995; Connors et al. 1996). The diameter of these cenotes on the YP varies from a few meters to more than $100 \mathrm{~m}$ (Schmitter-Soto et al. 2002). The cenotes were classified according to their formation process and their geometry as: caves, jug-shaped, cylindrical, and plate-shaped cenotes (Hall 1936). Navarro-Mendoza (1988) and Marín (1990) differentiated between coastal cenotes, which are shallower (3-35 $\mathrm{m}$ deep), and inland cenotes, which have depths greater than $100 \mathrm{~m}$ and walls up to $20 \mathrm{~m}$ high. Thus, the unique direct connection between surface and subterranean water bodies is firstly marked by groundwater cropping out in the cenotes through fractures and dissolution features (Schmitter-Soto et al. 2002). Secondly, on the YP, groundwater also surfaces through a mosaic of freshwater wetlands consisting of sloughs, channels, floodplains, and marshes (Gondwe et al. 2010b).

This study was motivated by the necessity to retrieve new hydrological datatypes that provide, in the short term, the opportunity to improve understanding of the karst aquifer and enhance knowledge of groundwater/surface-water interaction. Hydraulic measurements are important to promote the establishment of natural protected areas (hydrogeological reserves) that preserve adequate water quality for the population (Escolero et al. 2000) and groundwater dependent ecosystems (e.g. Kløve et al. 2011). Water surface elevation (WSE) observations can inform hydrogeological models to improve knowledge of the piezometric surface, groundwater flow streamlines, and to understand how water bodies are connected in the complicated YP karst aquifer. Bathymetry observations are important to compute the volume of surface water and identify fractures and caves in the bed of the water bodies. However, in-situ hydraulic observations of bathymetry and water surface elevation are generally labour-intensive, especially in the deep cenotes or in water bodies located in the jungled and remote areas. Thus, the aim of this study is to demonstrate that unmanned aerial vehicles (UAVs) are able to retrieve a new airborne real-time observational dataset, including bathymetry and WSE, in the floodplains and cenotes of the YP with an unprecedented flexibility, high accuracy and high spatial resolution.

\subsection{Water surface elevation observations}



Groundwater and surface water levels on the YP have traditionally been collected manually by field operators. However, lack of resources, inaccessibility due to dense vegetation, the size of the area, and the poorly developed terrestrial communication network restrict coverage of large areas or establishment of widespread monitoring networks. Changes in WSE can be observed with synthetic aperture radar interferometry (InSAR) in wetlands. Alsdorf et al. (2001) established that the accuracy of InSAR WSE observations is within a few centimetres for the L-band. Lu et al. (2005) demonstrated that also C-band InSAR can be used for monitoring WSE changes, with an accuracy that is potentially less or equal to $2 \mathrm{~cm}$ (Lu and Kwoun 2008). Gondwe et al. (2010) confirmed that InSAR data (RADARSAT-1 with HH polarization) can be used in the wetland of the Sian Ka'an reserve, located in YP, with an accuracy of few $\mathrm{cm}$.

However, there are several constraints in using InSAR data for monitoring the WSE: i) In-SAR data rely on vegetation emerging from the water body that allows for a sufficient coherence of the backscattered signal. Generally, only water surface positioned beneath vegetation (e.g. swamp forest, saline marsh, brackish marsh) can be monitored. Indeed, reflection from the water surface is generally specular (Alsdorf et al. 2000) and WSE can be monitored with InSAR only in case of double bounce scattering. Thus, it requires the signal to be reflected twice, i.e. first by the water surface and secondly by vertical vegetation elements such as tree trunks or grass. ii) InSAR cannot measure the changes in absolute WSE, because phase differences between near pixel values of interferograms only observe the relative temporal displacement of water surface. Therefore, in situ measurements at a location within the interferogram are needed to convert from relative WSE changes into absolute WSE (Gondwe et al. 2010a).

Only radar altimeters can measure absolute WSE; however space-borne radar altimeters face limitations in monitoring WSE: low accuracy, spatial and temporal resolution (Schumann and Domeneghetti 2016). Spaceborne altimeters have an accuracy of few decimetres (Calmant et al. 2008; Domeneghetti et al. 2015), which is suboptimal for many hydrological applications. In addition, they have a footprint that is in the order of several hundreds of meters (Asadzadeh Jarihani et al. 2013; Villadsen et al. 2015; O’Loughlin et al. 2016; Biancamaria et al. 2017), which results in a spatial resolution too coarse for monitoring the small and adjacent water bodies of the YP. 
On the other hand, UAVs have a tremendous potential in environmental monitoring, because they can potentially be used to remotely sense hydraulic observations in remote, inaccessible and dangerous areas (Klemas 2015; Tauro et al. 2016). The technology described by Bandini et al. (2017a) opened up the possibility of monitoring WSE from UAVs with high accuracy (better than $7 \mathrm{~cm}$ ) and optimal spatial resolution, allowing retrieval of WSE also in small lakes and narrow rivers.

\subsection{Bathymetry observations}

Bathymetry observations are generally collected in-situ with manned vessels. On the YP, inflatable dingles or canoes equipped with echo sounders are generally employed to retrieve observations of open water bodies. These in-situ surveys generally allow for a good coverage of the water body area with an accuracy that depends on the echo sounders performance. These surveys can be easily conducted in wetlands and open-sky plateshaped cenotes, but require a minimum water depth to navigate and are difficult to conduct in jug-shaped or cylindrical cenotes. Furthermore, vessels generally need to be towed to the water body by a road vehicle (Ore et al. 2015), while many water bodies are located in the jungled and remote areas, thus are difficult to access.

Remote sensing techniques can overcome the limitations of in-situ observations. The most common remote sensing techniques to measure bathymetry are: (i) LIDAR observations, (ii) through-water photogrammetry, iii) methods based on estimating water depth indirectly from the radiometric properties of multispectral images. These techniques generally require shallow and clear water bodies.

Bathymetric LIDARs are rarely implemented in UAVs, because of the trade-off between their performance and size or cost. Because of these limitations, accurate bathymetric LIDARs are generally too heavy for being transported by UAVs and require manned aircrafts. The lightweight innovative LIDAR Bathymetric Depth Finder BDF-1, which was recently presented by RIEGL, is one of the first lightweight ( 5.3 kg) and compact LIDARs available on the UAV market specifically developed for bathymetry surveys. However, this profiler LIDAR can retrieve measurements only up to 1-1.5 times the Secchi depth (Mandlburger et al. 2016) and requires a large UAV platform (around $20 \mathrm{~kg}$ ) to be operated.

Through-water photogrammetry involves digital photogrammetry to map the submerged topography applying photogrammetric techniques, after correcting for the difference between the refractive indices of water and air. Two-media photogrammetric methods have been applied to both aerial (Westaway et al. 2000, 2001) and 
UAV-borne images (Woodget et al. 2015). However, the photogrammetric solution relies on the identification of the homologous point pairs by using automated stereo-matching techniques (Lane et al. 2010). Water turbidity, water surface roughness, and maximum light penetration depth reduce the accuracy (Feurer et al. 2008; Marcus et al. 2012) and can even suppress the signal of the bed texture on the imagery (Lane et al. 2010). For these reasons, the applicability of through-water photogrammetry is limited and not suitable for most of the water bodies on the YP.

Although the majority of the surveyed cenotes and lagoons are several meters deep, in some cases, the water was sufficiently clear and with a bottom reflectance suitable for estimating bathymetry with optical techniques. In this context, Flener et al. (2013) reported a method to determine bathymetry from UAVs, exploiting reflectance in the optical range based on Lyzenga's algorithm widely used with satellite datasets (Lyzenga 1981). However, spectral-depth remote sensing is generally applied only to rivers with a depth of less than 1$1.5 \mathrm{~m}$ (Legleiter et al. 2004; Carbonneau et al. 2006; Legleiter 2012) because of the limited penetration depth of natural light. Moreover, reflectance-depth relationships are affected by substrate type, water surface roughness, and water column optical properties (Winterbottom and Gilvear 1997; Lejot et al. 2007; Legleiter et al. 2009; Bergeron and Carbonneau 2012; Legleiter 2014). The assessment of the potential of these methods would require flights at a sufficient height to capture each water body in one single picture (i.e. altitude of several hundreds of meters), otherwise incoming radiation, sun and camera's angles should be recorded to correct for their effect on the image brightness.

Similarly the potential of satellite high-resolution images (e.g. WorldView, IKONOS, QuickBird) has already been assessed in many scientific papers (e.g. Eugenio et al., 2015; Mishra et al., 2004; Ohlendorf et al., 2011; Stumpf et al., 2003) and have been applied also over the very shallow Caribbean sea reef around the YP (Cerdeira-Estrada et al. 2012). However, high-resolution satellite images are only commercially available. In this context, the potential of "open-access" medium-resolution satellite images, such as Landsat 8 satellite multispectral images, for estimating bathymetry has already been evaluated by other researchers, especially in coastal environments (Jagalingam et al. 2015; Pacheco et al. 2015).

Bandini et al. (2017b) reported the possibility to measure bathymetry with a tethered floating sonar controlled by the UAV. This technology was considered as a promising alternative to airborne LIDARs and opticalderived bathymetry. In this study, a tethered sonar, which can be controlled by lightweight UAVs, showed 
good performance in deep water bodies with variable water turbidity and bottom substrate. Furthermore, sonar-derived measurements are valuable to calibrate and validate Landsat 8 reflectance-depth relationships.

\section{Materials and methods}

For this proof-of-concept study, an off-the-shelf DJI hexa-copter Spreading Wings S900 multi-copter platform equipped with DJI A-2 flight controller (Fig. 1) was used.

(a)

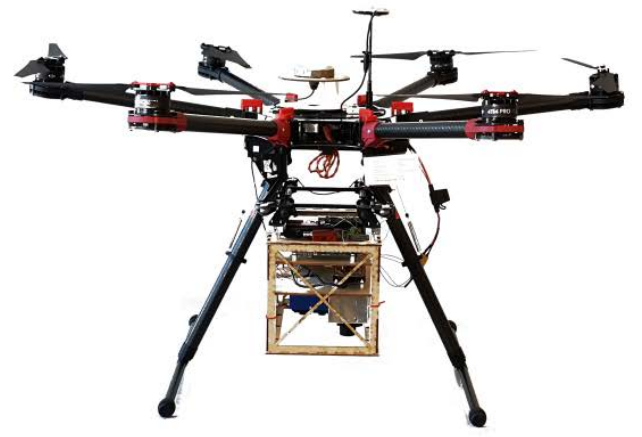

Fig. 1 (a) Hexacopter DJI Spreading Wings S900. The wooden box hosts the UAV payload. (b) The hexacopter during a flight above a lagoon.

Two different cameras were used during the flights: a Sony DSC-RX100, for flights requiring finer resolution and less distorted images, and a fish-eye lens Eken H9 camera for flights requiring images with larger field-ofview.

The on-board inertial measurement unit (IMU) was a Xsense MTi 10-series. The IMU measures the linear and angular motion of the UAV with a triad of gyroscopes and accelerometers, while a magnetometer measures the heading (angle between the drone's nose and the true north direction). The on-board global navigation satellite 
system (GNSS) consisted of a NovAtel receiver (OEM628 board) and an Antcom (3G0XX16A4-XT-1-4-Cert) dual-frequency global positioning system (GPS) and GLONASS flight antenna. The differential GNSS system required the installation of a static base station.

\subsection{Base station of the differential GNSS system}

A GNSS station was installed on the top of a building located in Felipe Carrillo Puerto, Quintana Roo. The antenna was secured for stability and positioned very close to the roof surface to avoid multipath errors, in a location with a clear view of sky. The GNSS antenna installed on the roof served as the base station for the position solution of the differential carrier-phase GNSS system, with the rover antenna located on the drone. The base station was a NovAtel receiver (Flexpack6) with a NovAtel GPS-703-GGG pinwheel triple frequency GPS and GLONASS antenna. The accurate position of the base station had to be computed in an international geodetic reference.

A second GNSS antenna, which was part of the Mexican "National Geodetic Network" and is located in Chetumal (Quintana Roo), was used as reference station. Observations of this second antenna were available on the website of Mexican institute “Instituto Nacional de Estadística y Geografía” (INEGI 2013). The position of this second antenna was provided in the reference frame ITRF2008 at 2010.0 epoch, with reference ellipsoid GRS80. To compute the absolute position of the base station used for this study, a carrier-phase differential solution was computed in post-processing using the INEGI antenna as master station of known coordinates. Carrier-phase differential GNSS allows corrections for most of all the GNSS errors that are in common between the receivers (e.g. satellite orbit errors, satellite clock errors, atmospheric errors). Only multipath errors and noise of the individual receivers are uncorrelated and cannot be corrected in differential mode. However, the baseline between the two antennas is of $\sim 120 \mathrm{~km}$ (Fig. 2). Due to the length of this baseline, the errors of the receivers (e.g. satellite orbit, atmospheric errors) are slightly different. Thus, the position of the base station installed for this study could not be retrieved with an accuracy of few mm: the absolute accuracy of the position in the ITRF2008, epoch 2010.0 of the base station is assumed $\sim 3 \mathrm{~cm}$. The coordinates of the two antennas are shown in Table 1. 

2010.0 epoch.

\begin{tabular}{|l|l|l|l|l|}
\hline Antenna Location & Operator & Latitude (N) & Longitude (W) & $\begin{array}{l}\text { Ellipsoidal Height } \\
(\mathrm{m})\end{array}$ \\
\hline Chetumal & INEGI & $18^{\circ} 29^{\prime} 42.99641^{\prime \prime}$ & $88^{\circ} 17^{\prime} 7.20961^{\prime \prime}$ & 2.955 \\
\hline Felipe Carrillo Puerto & $\begin{array}{l}\text { Installed for this } \\
\text { study }\end{array}$ & $19^{\circ} 34^{\prime} 54.03868^{\prime \prime}$ & $88^{\circ} 02^{\prime} 34.73677^{\prime \prime}$ & 10.5031 \\
\hline
\end{tabular}

210

(a)

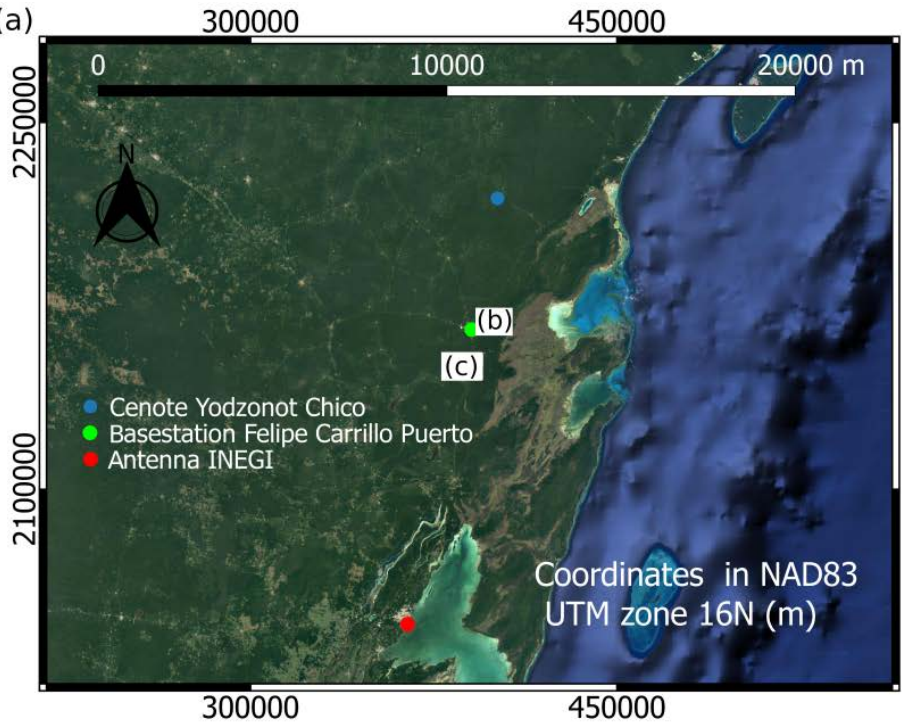

(b)

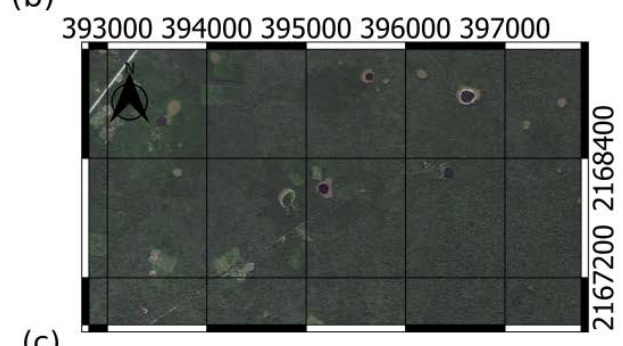

(c)

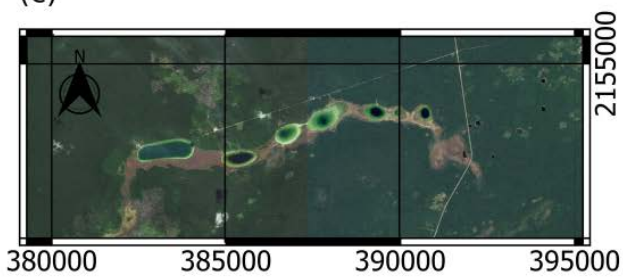

Fig. 2 (a) Map showing the two static GNSS antennas (antenna located in Chetumal belonging to INEGI's network and antenna located in Felipe Carrillo Puerto used as base-station during the flights). Cenote XII

218 (Yodzonot Chico) is highlighted with a blue circle in (a). The investigated cenotes and lagoons are shown in (b)

219 and (c) and in Fig.5 with magnified images. Background map retrieved from Google Earth (2017). 
222 Flights were conducted in February and March 2017 with the objective to monitor the lagoons and the cenotes 223 listed in Table 2, which are located in the state of Quintana Roo, Mexico.

Table 2. Location of the water bodies surveyed with the UAV. The name of some water bodies is not available (-).

\begin{tabular}{|c|c|c|c|}
\hline $\begin{array}{l}\text { Water body } \\
\text { Identification } \\
\text { Number }\end{array}$ & Name of the water body & Locality & $\begin{array}{l}\text { Coordinates in UTM, zone 16N, } \\
\text { NAD83 reference system. } \\
\text { x [easting], y [northing]. (m) }\end{array}$ \\
\hline I. & Laguna Noh-Cah & Noh-Cah & $376988.541,2147788.459$ \\
\hline II. & $\begin{array}{c}\text { Laguna Ocom } \\
\text { Santa Isabel }\end{array}$ & Santa Isabel & $383511.933,2152574.494$ \\
\hline III. & Laguna Pucté & Ocom & 386623.799, 2152920.257 \\
\hline IV. & Laguna Balam Nah & Ocom & $387776.341,2153358.224$ \\
\hline V. & Laguna Síijil Noj Ha' & Ocom & $389320.749,2153519.580$ \\
\hline VI. & Laguna - & Ocom & 390749.902, 2153588.732 \\
\hline$\overline{\text { VII. }}$ & Cenote K’ux Chúuk & Chancah-Veracruz & $394103.801,2154505.004$ \\
\hline VIII. & Laguna - & Felipe Carrillo Puerto & 394818.378, 2167972.467 \\
\hline IX. & Laguna Vigía Chico & Felipe Carrillo Puerto & $395164.141,2168099.246$ \\
\hline $\mathrm{X}$. & Cenote Vigía Chico & Felipe Carrillo Puerto & $396437.701,2168266.365$ \\
\hline XI. & Laguna - & Felipe Carrillo Puerto & $396604.819,2169032.806$ \\
\hline XII. & Cenote Yodzonot Chico & Chumpón-Tepich & 401107.368, 2218977.181 \\
\hline
\end{tabular}

\subsection{Payload for UAV-borne WSE observations}

The payload consisted of a radar and the GNSS system. Bandini et al. (2017a) described the WSE measuring system, including the rationale for the sensor selection, post-processing methods, and system accuracy. As described in the cited paper, the radar is the ARS 30X developed from Continental. WSE is measured by 
subtracting the range to the water surface (range measured by the radar) from the drone altitude (retrieved by

234 the GNSS system) above the reference ellipsoid. Observations can be filtered with a low-pass filter as described in Bandini et al. (2017a) and corrected to compensate for the drone roll and pitch angles retrieved by the IMU.

The base station in Felipe Carrillo Puerto is used for GNSS augmentation to improve the drone position accuracy. The baseline between the base and the rover station is less than $15 \mathrm{~km}$ for all the flights except the flight above cenote XII, which is $\sim 55 \mathrm{~km}$. WSE above the reference ellipsoid can be converted into orthometric height, i.e. meters above mean sea level ( $\mathrm{m}$ amsl), if the geoid undulation is known. An online program to convert coordinates from the GRS80 ellipsoid to the GGM10 geoid, which is the reference gravimetric model for Mexico, is available on the INEGI website.

WSE measurements were carried out in all the water bodies listed in table 1 . The Water Body XII (Cenote Yodznot Chico) was included because of its jug-shaped geomorphology (Hall 1936), although it is located 50$60 \mathrm{~km}$ away from the other investigated water bodies. In this cenote, the free-surface water table is several meters below ground level. It features the prototypical cenote morphology that is representative for the cenotes located in the ring of cenotes around Mérida. This cenote is included to evaluate the performance of the UAVborne water ranging technology for such targets. Indeed, there are two main challenges in retrieving water surface elevation in these water bodies. First, the small aperture of the cenote precludes a flight inside the small cavity. Indeed, a flight inside the sinkhole would be ideal to have a clear view of the water surface but it would cause a complete loss of the GNSS signal. Thus, the flight has to be performed above the sinkhole, but the dense vegetation overhanging and surrounding the aperture of the cenote complicates flight manoeuvres and degrades the GNSS signal, which is necessary for measuring water surface elevation. Secondly, the radar signal may potentially be affected by multipath disturbance from the walls of the cenote (Bandini et al. 2017a). 


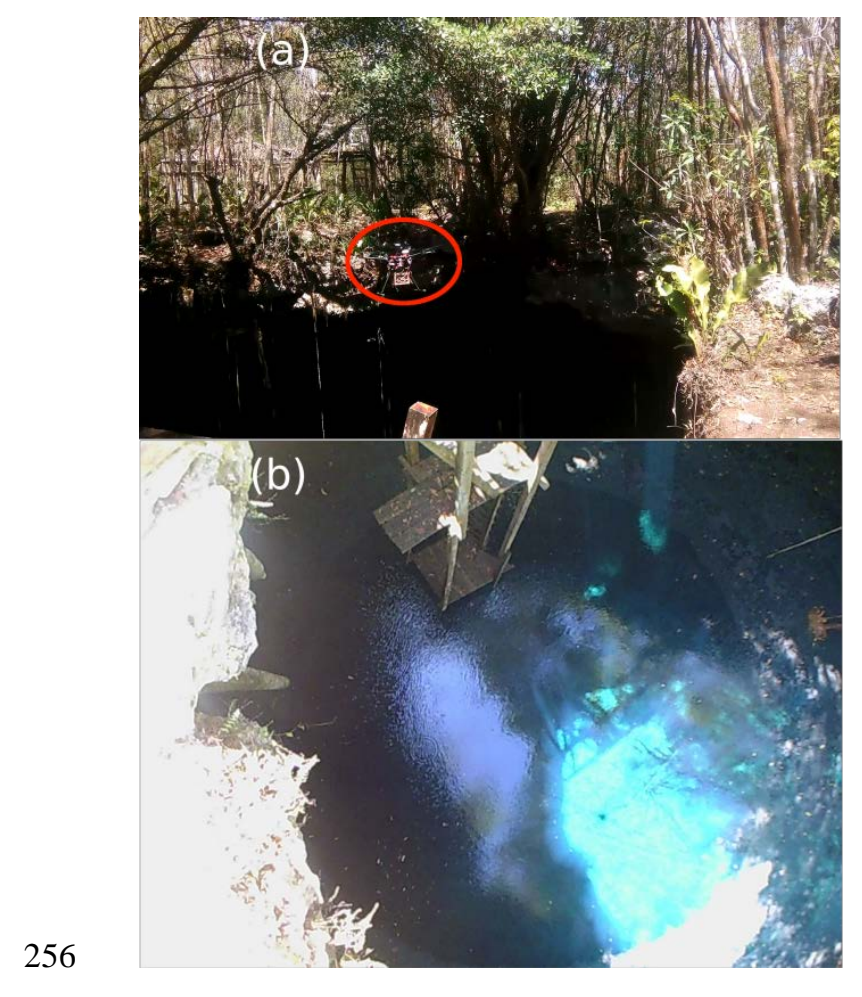

Fig. 3 (a) Video frame of the flight above the jug-shaped cenote (Water Body XII). The UAV is highlighted with a red circle. Vegetation overhanging the cenote complicates the computation of the position solution from the GNSS observations. (b) UAV-borne picture of the cenote.

\subsubsection{Ground truth for water surface elevation}

For some water bodies, UAV-borne WSE observations were compared with the ground-truth observations retrieved by a GNSS rover station (Leica Viva GS10). Similarly to Gondwe et al. (2010), the antenna of this station is manually positioned in a location closed to the water body where it can track several satellites (i.e. in clear open sky) for 15 minutes or more. Through levelling techniques, the offset between the position, where the rover station is placed, and the water surface is measured. In this way, accurate WSE determination is possible. Ground truth observations GNSS-based observations are also processed with carrier-based differential method using the observations of the base-station in Felipe Carrillo Puerto. Compared to the UAV-borne observations, in-situ measurements obtained with this rover station have the advantage of excluding the inaccuracy of the radar system and of averaging GNSS observations in a static mode for a long time. A vertical 272 accuracy of $\sim 4-5 \mathrm{~cm}$ is achievable with this static GNSS differential system. 
276 Surveys to reconstruct bathymetry were conducted only in a subset of the water bodies of Table 2 (water bodies III, IV, V, VII, X). Bathymetry observations are obtained with a tethered sonar sensor controlled by the drone. The single beam sonar is the Deeper Smart Sonar PRO+ developed by the company Deeper, UAB. It allows retrieval of water depth with an accuracy of $\sim 3.8 \%$ of the depth for a maximum depth potentially up to $80 \mathrm{~m}$. If waveform analysis is accurately handled, the success of the bathymetric surveys is not affected by water turbidity, bed material, and topography. The accurate position of the sonar is determined relatively to the UAV platform position. Technical details of this measuring system are described in Bandini et al. (2017b). Fig. 4 shows the tethered sonar and its measuring beam. 


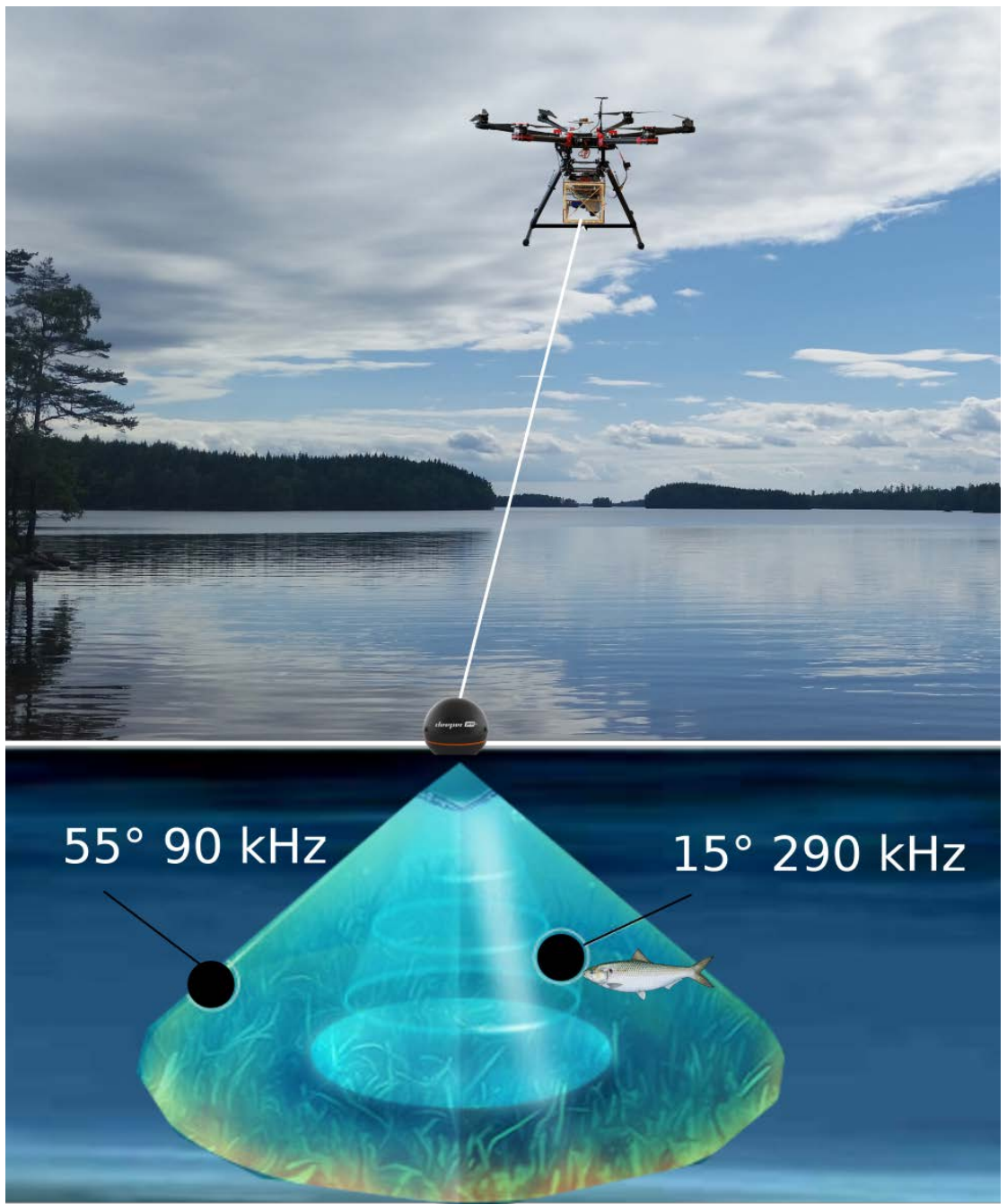

Fig. 4 Sketch of the tethered sonar. The sonar has two measuring beams at two different frequencies: $55^{\circ}$ at 90 $\mathrm{kHz}$ and $15^{\circ}$ at $290 \mathrm{kHz}$. The higher frequency is used for bathymetric survey, while the lower frequency is generally preferred for other applications (e.g. to identify fish).

\subsubsection{Correlation between water depth and spectral signature of satellite images}

Optical-derived bathymetry is generally based on a Beer-Lambert radiative transfer of light in water (equation

(1)), in which $D$ is the depth, $L_{i}$ is the radiance in the $i^{\text {th }}$ wavelength, $L_{i \infty}$ is the average signal over deep water, 
$c_{i}$ is a function of several optical parameters (e.g. solar irradiance, atmosphere and water transmittance, and water surface reflectance), $A_{b i}$ is the bottom (b) albedo in the $i^{\text {th }}$ wavelength, and $K_{i}$ is the diffuse attenuation coefficient (Jerlov 1976). Solving for optical depth, $D$, one obtains equation (2):

$$
\begin{gathered}
L_{i}=L_{i \infty}+c_{i} \cdot A_{\mathrm{b} i} \cdot e^{-2 k_{i} D} \\
D=\frac{\ln \left(c_{i} A_{\mathrm{b} i}\right)}{2 k_{i}}-\frac{\ln \left(L_{i}-L_{i \infty}\right)}{2 k_{i}}
\end{gathered}
$$

Assuming that the water and the bed sediment reflectance are homogeneous, that background optical effects and solar irradiance are constant, and that the water column is uniform, equation (3) can be derived with $A_{0}$ and $A_{1}$ as constant coefficients. Alternatively, if observed reflectance $\left(R_{i}\right)$ is considered instead of radiance, the equation shown in (4) holds, derived with $B_{0}$ and $B_{1}$ as constant coefficients.

$$
\begin{aligned}
& D=A_{0}+A_{1} \cdot \ln \left(L_{i}-L_{i \infty}\right) \\
& D=B_{0}+B_{1} \cdot \ln \left(R_{i}-R_{i \infty}\right)
\end{aligned}
$$

To prove that sonar observations can also be used to calibrate and validate optical-derived bathymetry measurements, the relationship between the top of atmosphere (TOA) reflectance of the Landsat 8 panchromatic band, which is the Landsat band with the highest spatial resolution $(15 \mathrm{~m})$, and the bathymetry observations retrieved by the sonar was computed. The dark pixel $\left(R_{i \infty}\right)$ subtraction is essential to identify the logarithmic correlation (Stumpf et al. 2003; Mohamed et al. 2016). In the bathymetry maps shown in the Results section, DigitalGlobe imagery obtained from Google Earth (2017) shows the land surface surrounding the water bodies, while the water bodies are represented in a grey scale displaying the TOA reflectance of the eighth band (panchromatic) of Landsat 8, 8-day composite (17th-25th January 2017). Landsat 8 imagery was directly downloaded from Google Earth Engine (Gorelick et al. 2016). Conversion from 8-bit digital number (DN) to TOA Reflectance is performed by the processing methods implemented by Google Earth Engine. First the DNs are converted into radiance values, using the bias and gain values specific to the individual 

solar elevation and seasonally variable Earth-Sun distance (Chander et al. 2009).

\section{Results}

Table 3 shows the WSE measurements obtained by the UAV-borne instrumentation during each single flight.

Table 3: WSE observations retrieved in the different water bodies. The table shows the mean and the standard station are also reported. In some water bodies, ground truth observations are not available (-).

\begin{tabular}{|c|c|c|c|c|c|}
\hline \multirow{2}{*}{$\begin{array}{c}\text { Water body } \\
\text { Identification } \\
\text { Number }\end{array}$} & \multirow{2}{*}{$\begin{array}{l}\text { Mean of UAV- } \\
\text { borne WSE } \\
\text { observations [m } \\
\text { amsl] }\end{array}$} & \multirow[b]{2}{*}{$\begin{array}{c}\text { Standard } \\
\text { Deviation of } \\
\text { UAV-borne } \\
\text { WSE } \\
\text { observations } \\
\text { [cm] }\end{array}$} & \multicolumn{2}{|c|}{ Flight statistics } & \multirow{2}{*}{$\begin{array}{c}\text { LEICA rover } \\
\text { station } \\
\text { (ground truth) } \\
\text { [m amsl] }\end{array}$} \\
\hline & & & $\begin{array}{l}\text { Maximum flight height } \\
\text { [m above ground level] }\end{array}$ & $\begin{array}{c}\text { Flight time above } \\
\text { lagoon } \\
\text { [sec] }\end{array}$ & \\
\hline I. & 1.20 & 3 & 48 & 140 & - \\
\hline II. & 1.14 & 5 & 50 & 300 & $1.16 \pm 0.06$ \\
\hline III. & 1.13 & 3 & 65 & 140 & $1.10 \pm 0.05$ \\
\hline IV. & 1.13 & 4 & 80 & 270 & $1.12 \pm 0.04$ \\
\hline V. & 1.10 & 11 & 112 & 265 & $1.07 \pm 0.05$ \\
\hline VI. & 1.09 & 3 & 45 & 300 & - \\
\hline VII. & 1.02 & 3 & 53 & 270 & - \\
\hline VIII. & 1.05 & 5 & 62 & 350 & - \\
\hline IX. & 1.05 & 10 & 112 & 250 & $1.02 \pm 0.05$ \\
\hline $\mathrm{X}$. & 1.02 & 6 & 59 & 270 & - \\
\hline
\end{tabular}




\begin{tabular}{|c|c|c|c|c|c|}
\hline XI. & 1.02 & 10 & 101 & 430 & - \\
\hline XII. & 0.8 & 50 & 12 & 370 & $0.90 \pm 0.15$ \\
\hline
\end{tabular}

328 Table 3 shows that there is a good agreement between the ground-truth observations and the UAV-borne 329 observations; however, accuracies of both systems vary from site to site. Ground-truth GNSS measurements

330 have an accuracy of $\sim 5 \mathrm{~cm}$. As shown in Table 3, the standard deviation of the UAV-borne observations is 331 within $11 \mathrm{~cm}$ for all the flights except for the last one (flight above cenote XII), which is $\sim 50 \mathrm{~cm}$. The mean 332 values of UAV-borne WSE observations show an accuracy within 5-7 $\mathrm{cm}$ when compared to the in-situ 333 observations, except that for cenote XII. In the cenote XII, the accuracy of UAV-borne observations degrades 334 but also ground truth is considered less accurate than for the other cenotes. Indeed, in this cenote a water level 335 dip meter had to be deployed together with the GNSS and the levelling station. The dip meter was used to 336 measure the range from the ground level to the cenote water surface. An overall system accuracy of $\sim 15 \mathrm{~cm}$ 337 was achieved for the in-situ measurements in cenote XII.

338 A map of the UAV-borne measurements in the water bodies, numbered from I up to VII, is shown in Fig. 5. 


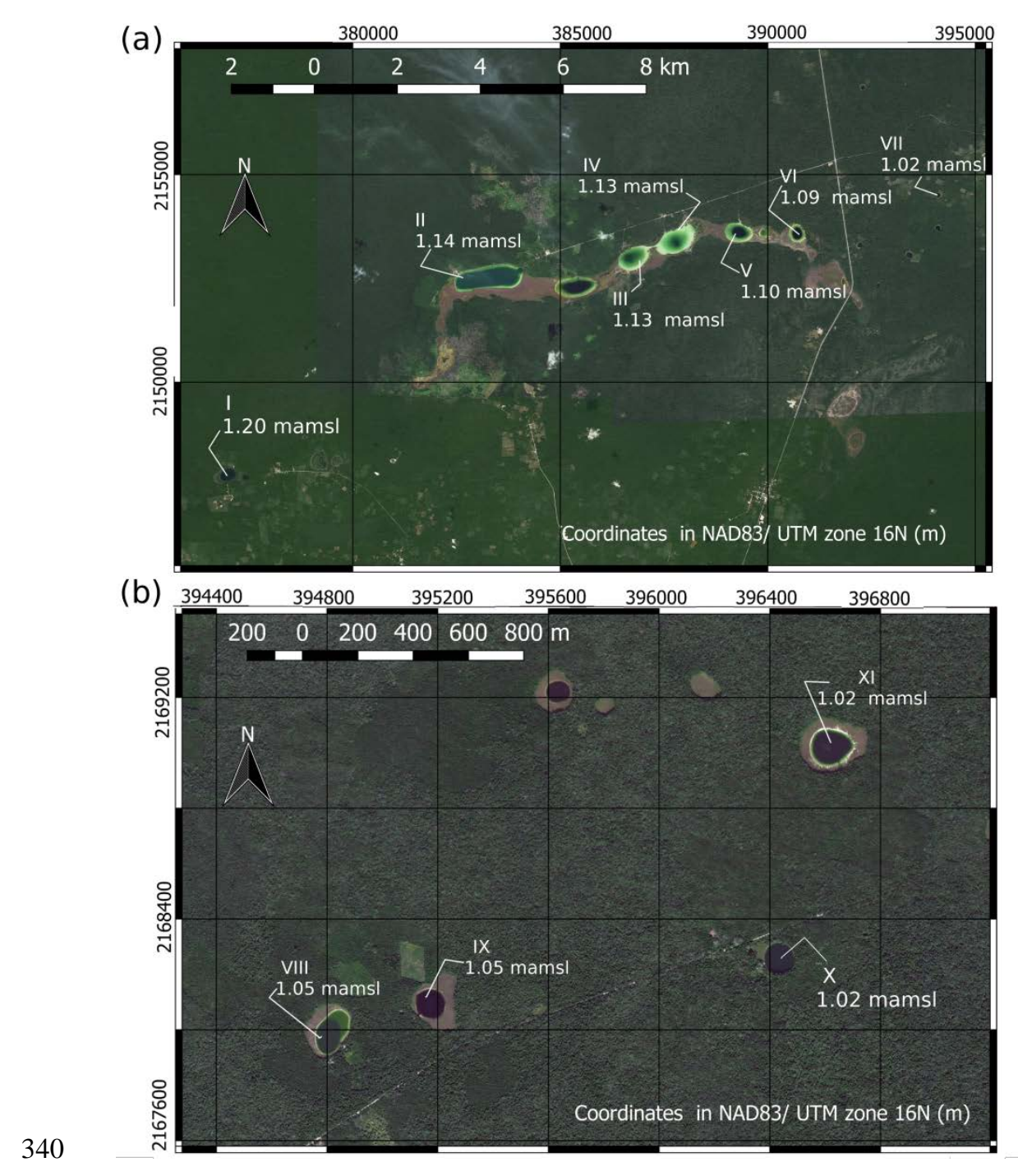

341 Fig.5 UAV-borne WSE (m amsl) observations. (a) Water bodies from I up to VII. (b) Water bodies from VIII 342 up to XI.

344 Fig. 5 shows that WSE decreases consistently from West to East, in the direction of the nearby ocean, with a 345 water-table slope of a few $\mathrm{cm} / \mathrm{km}$. In the water bodies from I up to VII, represented in Fig $5 \mathrm{a}$, there is a 346 difference of $18 \mathrm{~cm}$ between the westernmost and easternmost water body over a distance of $18.4 \mathrm{~km}$. This 347 slope is less than what other studies reported for this Pliocene area of the YP, e.g. 3-7 cm/km (Gondwe et al. 348 2010b), however, targets may not be aligned along a groundwater streamline. 
Fig. 6 shows an example of the UAV-borne WSE observations, specifically the observations retrieved during the flight above III.
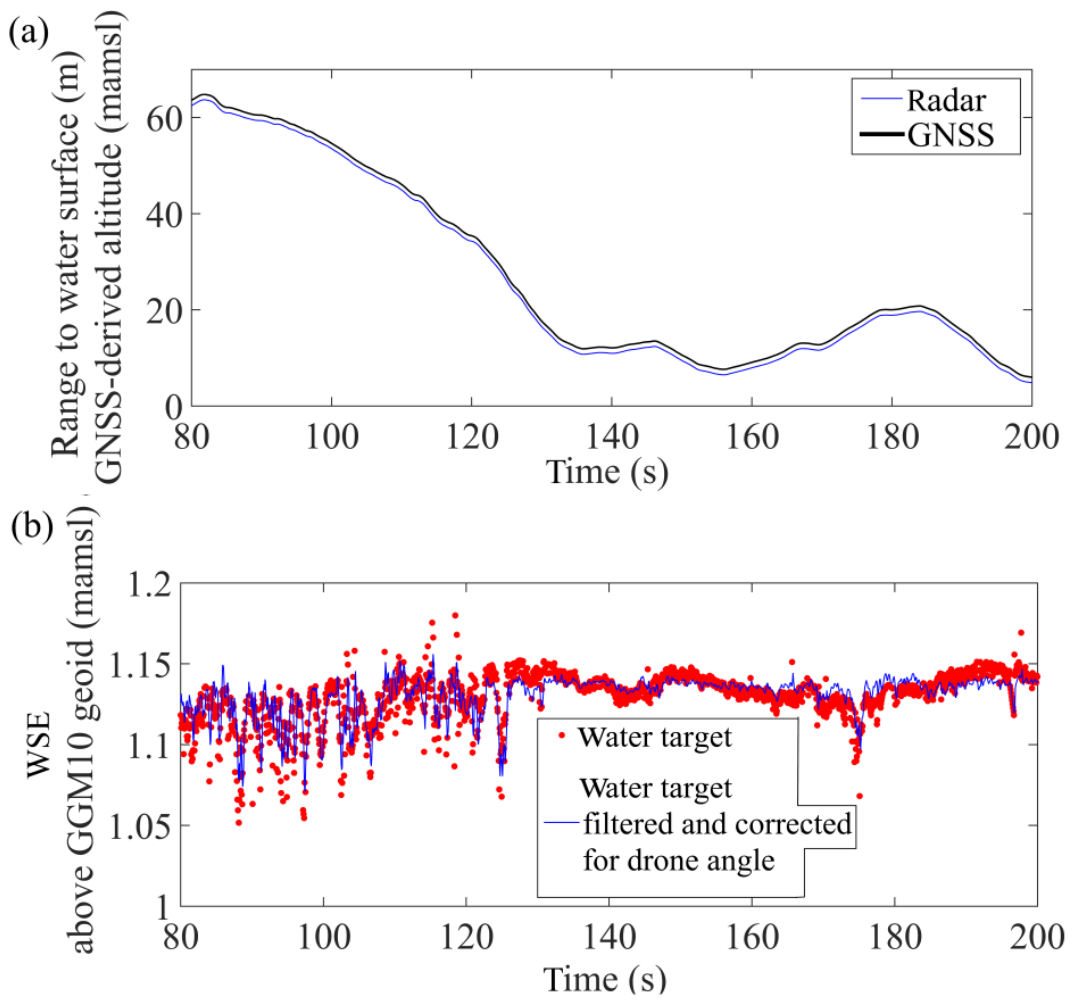

Fig. 6 Observations retrieved by the payload for measuring WSE during the flight above III. (a) Range to water surface is measured by the radar, and altitude above mean sea level is measured by the GNSS system. (b) Red dots are the raw WSE observations. Blue line shows observations that have been filtered and corrected for the pitch and roll angles of the drone.

The radar and the GNSS curves in Fig. 6 (a) show high correlation. The offset between the two curves should

360 be constant since the WSE in the lagoon is uniform. WSE observations are shown in Fig. 6 (b). Red colour dots show observations obtained by subtracting the radar observations (range to the water surface) from the GNSS altitude (drone altitude above mean sea level). The filtered WSE observations, which are represented with a blue line, have an average of $1.13 \mathrm{~m}$ and a standard deviation of $\sim 3 \mathrm{~cm}$. The standard deviation in the measurements is due to inaccuracy of the radar-GNSS integrated system. As described in Bandini et al. 
(2017a), the accuracy of the radar depends on the range to the water surface, while the accuracy of GNSS system is generally independent of flight height.

UAV-borne WSE measurements were more problematic in the jug-shaped water body XII (Cenote Yodzonot Chico), as shown in Fig. 7. Vegetation overhanging the water body complicated the computation of the position solution from the GNSS raw observations. Indeed the integer ambiguity of the GNSS signal was not entirely solved. IMU-GNSS integrated solutions, both loosely and tightly coupled (e.g. Groves, 2013; Noureldin et al., 2013), were tested but did not improve the GNSS solution positions. This was mainly caused by the disturbance on the GNSS signal during the GNSS-IMU initialization period caused by vegetation canopy. However, the radar successfully measured the range to the water surface, although this jug-shaped sinkhole exposes only a narrow field of view and its small ground aperture could potentially cause multipath effects of the radar signal. Nevertheless, the on-board radar retrieves the angle and the range of each target in its field of view, which makes it possible to identify the target representative of the water surface (Bandini et al. 2017a).
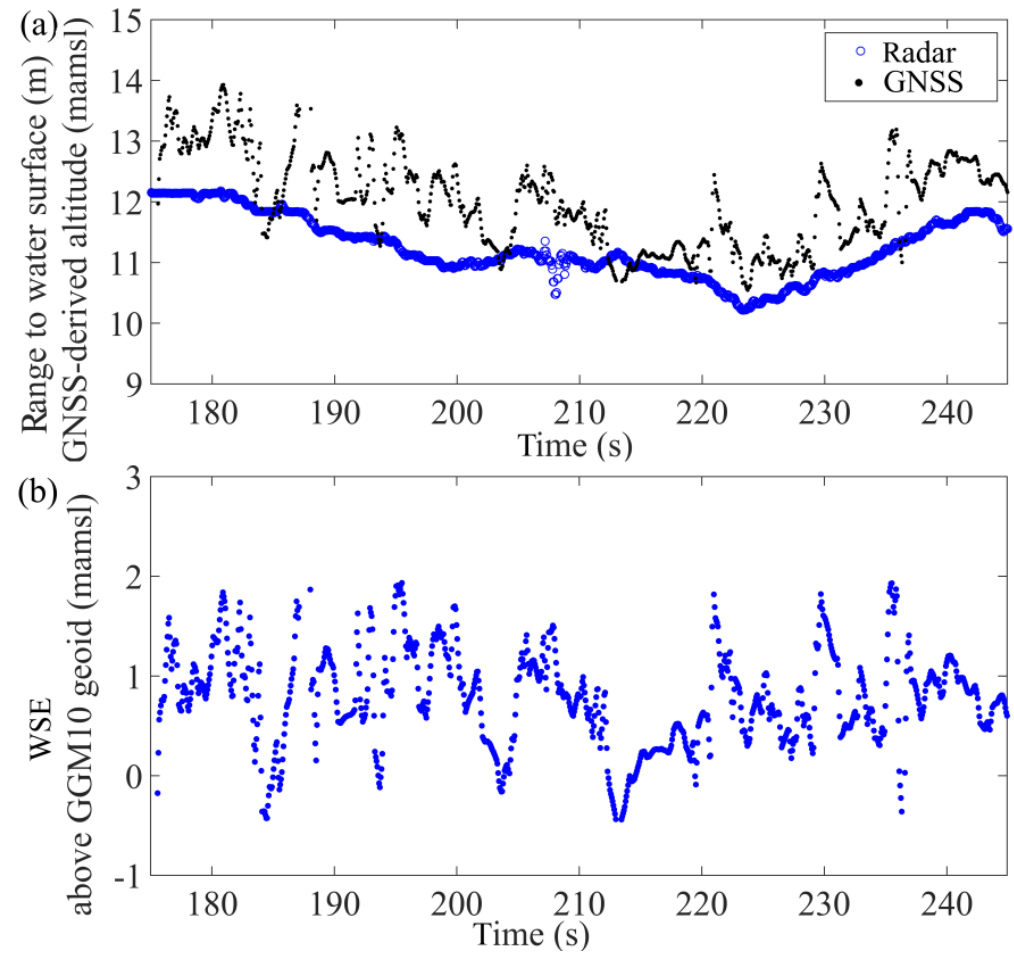

Fig. 7 Flight above Water Body XII (Cenote Yodzonot Chico). (a) Range measured by the radar and altitude measured by the GNSS system. (b) WSE observations. 


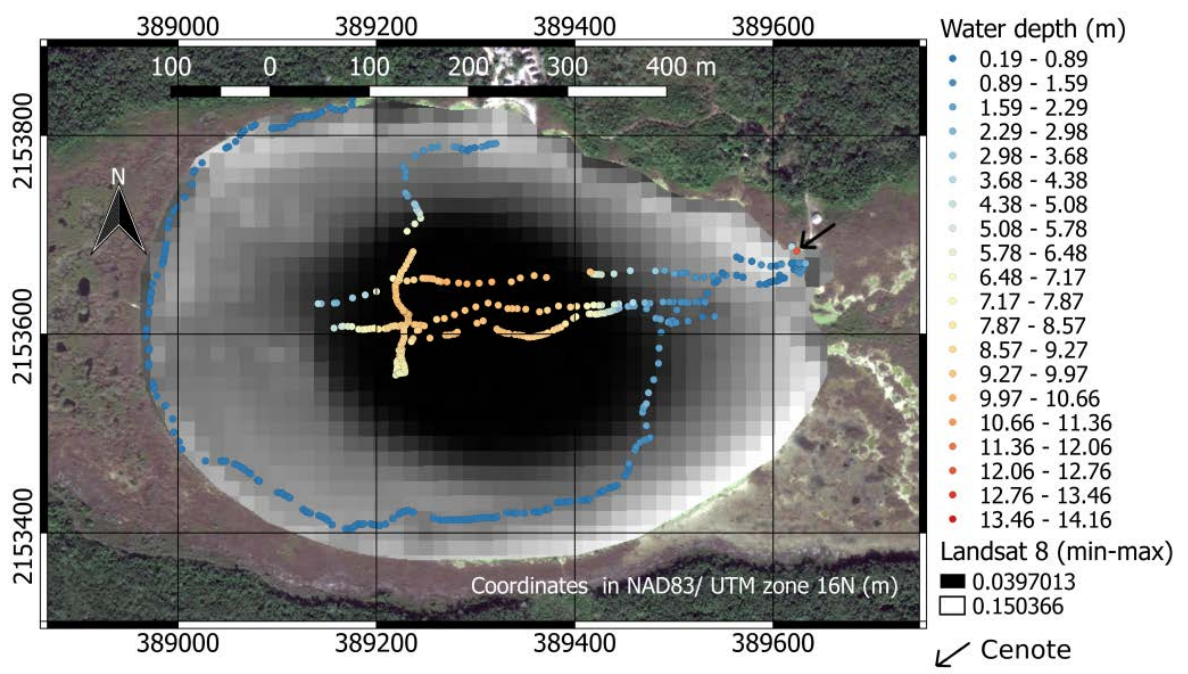

Fig. 8 Bathymetry observations in V (laguna Síijil Noj Ha').

As shown by Fig. 8, water depth is retrieved only in some points of the lagoon, i.e. the locations in which the tethered floating sonar is flown and placed in contact with the water surface. The orthometric elevation of the wet-bed can be computed by subtracting the water depth from the WSE measured in this lagoon (1.10 m amsl). The observations retrieved in the inner part of the lagoon depict a water depth between 8 and $10.5 \mathrm{~m}$ and fall into an area of low reflectance of Landsat 8. The deepest point of the lagoon is on the eastern outer area of the lagoon where there is a fracture zone in the lagoon bed that hosts a cenote (represented with the red dot depth observation), which has a maximum water depth of $\sim 14.15 \mathrm{~m}$. 
Water depth observations of Laguna Balam Nah, Pucté, cenote K’ux Chúuk, cenote Vigía Chico are reported in Appendix A. Laguna Balam Nah has a maximum depth of $4.65 \mathrm{~m}$, while the maximum in laguna Pucté is around $2.30 \mathrm{~m}$. In the cenote K’ux Chúuk (cenote located in Chancah-Veracruz) the maximum depth is 15.50 $\mathrm{m}$. The shallower outer part has a water depth of less than $2 \mathrm{~m}$, while the inner deeper area has a water depth of more than $11 \mathrm{~m}$. Cenote Vigía Chico presents an inner deep area covering most of its extension with a depth of more than $10 \mathrm{~m}$. On the western part of this cenote, there is a second smaller cenote, the maximum water depth of which is $\sim 11.2 \mathrm{~m}$.

The water depth maps have shown a good agreement with the reflectance of the panchromatic band of Landsat 8. Fig. 9 shows the relationship between reflectance and depth. The darkest pixel $\left(R_{\mathrm{i} \infty}\right)$, which was $\sim 0.038$, was subtracted from the reflectance observations.

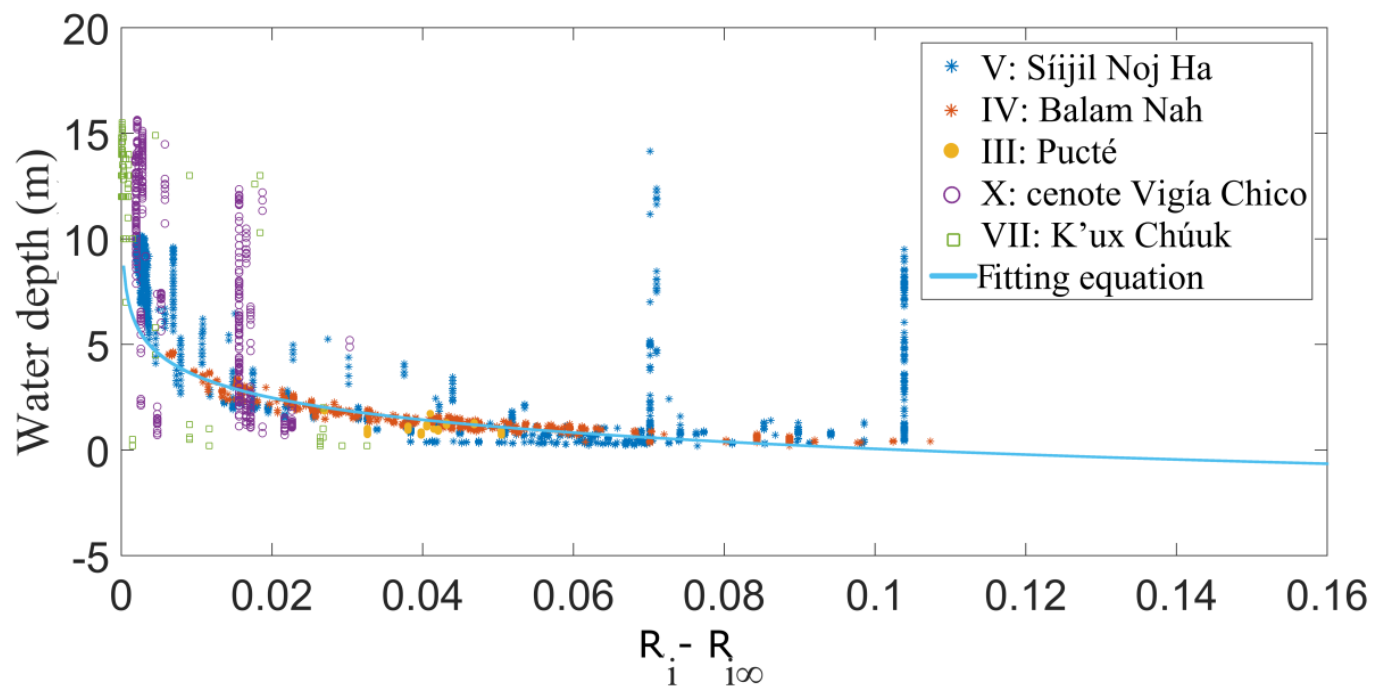

Fig. 9 Relationship between the bathymetry depth observations and $\left(R_{i}-R_{i \infty}\right)$ Landsat 8 reflectance values.

As shown by Fig. 9, a logarithmic law could be identified to estimate water depth, as shown in (5).

$$
D=-1.5 \cdot \ln \left(R_{i}-R_{i \infty}\right)-3.4
$$


However, the relationship showed a low $\mathrm{R}^{2}(\sim 0.6)$. The logarithmic law fails to estimate water depth values larger than $\sim 7 \mathrm{~m}$, threshold above which the curve is nearly a vertical line. Thus, Landsat panchromatic TOA reflectance cannot be considered as a robust proxy for water depth in deep water bodies. Furthermore, several outliers are visible. $\mathrm{V}$ and $\mathrm{X}$ are the water bodies with most outliers. The resolution of Landsat 8 images (15 $\mathrm{m}$ ) is the main reason for outliers. For example, in the water body $\mathrm{V}$ (lagoon) the resolution of Landsat 8 is unable to capture the deep area on the eastern side of the lagoon, where a collapse of the bed of the lagoon has created a sinkhole. For the water body X (cenote), Landsat 8 reflectance unexpectedly shows a majority of values that are either $\sim 0.04$ or $\sim 0.055$, which corresponds to $\sim 0.002$ and $\sim 0.017$ after dark pixel subtraction, while the bathymetry observations showed variable depth values.

\section{Discussion}

This section highlights the potential of UAVs for retrieving hydrological observations of WSE and depth. The advantages of using UAVs and their limitations are compared to traditional techniques.

\subsection{UAV-borne WSE measurements compared to in-situ traditional techniques}

Compared to Gondwe et al. (2010a), who manually took measurements of WSE using a GNSS rover station and a levelling network, UAVs do not require any levelling network. The levelling network was necessary for manual operators to measure the offset between the water surface and the GNSS antenna, which needs to be positioned in a clear open sky area. Secondly, the possibility to measure WSE in a deep sinkhole, where the water table is several meters below ground level, is demonstrated. These observations are generally complicated to be retrieved in situ by manual operators because they require the installation of water level dip meters, in addition to the levelling and GNSS network. This study demonstrated that the UAV-borne radar was capable of measuring the range between the UAV and the water surface of the cenote. However, the on-board GNSS signal was strongly affected by the canopy during flights above cenotes in the jungled areas. To improve the GNSS position solution, new IMU-GNSS integration solutions should be used. For instance, ultra-tight 
coupling, which is the highest integration level, generally shows good performance also in scenarios with low GNSS signal to noise ratio and less than 4 visible satellites (Olesen et al. 2017).

\subsubsection{Optimal UAV platform for hydrological observations}

The advantage of using a multi-copter, compared to a fixed wing UAV, is justified by the possibility to: i) takeoff and land vertically, ii) hover and accurately control its position to optimize GNSS signals. However, rotary wings UAVs are constrained by the limited flight time and low speed. An optimal solution for this monitoring task is the deployment of VTOL (Vertical Take-Off and Landing) hybrid UAVs. Such UAVs combine the advantage of fixed wing, such as flight endurance, and rotary wing, such as manoeuvrability. One of these advanced unmanned aircrafts is the hybrid platform developed in the Smart-UAV project, which is a collaboration between the Technical University of Denmark and the Danish company Sky-Watch (Knudsen et al. 2015; Bauer-Gottwein 2016; DTU and Sky-Watch 2017). The flight path for a potential hydrologic monitoring mission using a hybrid platform is shown in Fig. 10.

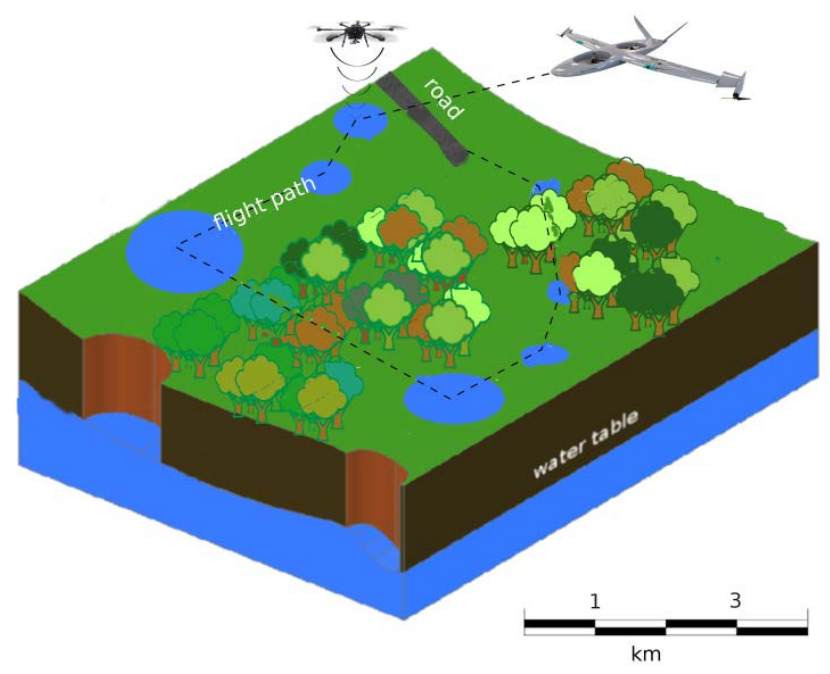

Fig. 10 Advantage of employing a hybrid VTOL UAV. The shown hybrid UAV is the platform developed for the SMART-UAV project. Drawing of the drones is not to scale.

As suggested by Fig. 10, multi-copters have a limited flight endurance (around 20 minutes), which makes it hard to cover a large area in a single flight and requires the operator to transport the platform to the surveyed 
area. A hybrid platform would relocate from target to target in efficient fixed-wing mode and hover over each target for a couple of minutes to acquire WSE readings. This would allow monitoring of remote and hardly accessible water bodies, such as the ones inside densely vegetated areas (jungle) of the YP. According to Beddows and Blanchon (2007), the number of cenotes is between 7000 and 8000 in the state of Yucatan alone; while, according to Amigos de Sian Ka'an and Colectividad Razonatura A.C. (2012), there are 5313 cenotes or suspected cenotes (e.g. collapses zones, vertical-walled open water cenote, etc.) in Quintana Roo. This number only includes the number of sinkholes, and does not consider the wetlands that are located throughout the YP. The majority of these water bodies are unexplored. Thus, a hybrid VTOL UAV could be used to establish a ground-based WSE monitoring program on the YP without the need of expensive drilling programs, making use of thousands of the free access points to the phreatic surface created by the cenotes and lagoons. However, such monitoring systems require high-performance hybrid platforms, and a legal regime that allows fully autonomous flights beyond visual line of sight.

\subsection{UAV-borne bathymetry measurements compared to in-situ traditional techniques}

At the current state, UAV platforms and sensors require an initial investment, pilot licensing or certification can be labour-intensive, and flight authorizations require a complex lengthy bureaucratic procedure. However, the potential of measuring WSE with UAVs is promising when compared to the use of manual operators and levelling networks.

Similarly, UAV-borne bathymetry observations can complement bathymetric observations retrieved with boats. The usage of boats is generally resource demanding, requires boat transportation from one water body to the other, and necessitates a minimum water depth to navigate. However, while the technology to monitor WSE is ready to be employed on a hybrid fully autonomous platform, water depth monitoring still presents numerous challenges. Indeed, the tethered sonar is an alternative to remote sensing methods based on spectral-depth relationships, which require shallow and clear water bodies, and to bathymetric LIDAR systems, which are generally too heavy for UAVs. However, dragging of the tethered sonar over the water surface can be performed only above open water surfaces and still relies on UAV piloting skills. UAV flights with the tethered sonar are difficult to perform in water bodies with dense aquatic vegetation and other obstacles. However, these herbaceous wetlands can be non-navigable also for manned and unmanned vessels. 
A logarithm relationship exists between the reflectance of the panchromatic band of Landsat 8 images and the water depth of the investigated water bodies. However, the relationship is weak, with numerous outliers and a low $\mathrm{R}^{2}$. Thus, more studies are necessary to evaluate the potential of commercial high-resolution satellite imagery in the inland water bodies of the YP. Moreover, methods considering multiple multispectral bands (e.g. Lyzenga's method) should be evaluated in this region. However, spaceborne or UAV-borne opticalderived remote sensing of bathymetry requires training data to calibrate depth-brightness or depth-reflectance relationships. Indeed, illumination, viewing geometry, water surface roughness, turbidity and bottom reflectance can vary across and between images (Legleiter and Roberts 2005; Lane et al. 2010). Thus, in-situ observations or UAV-borne sonar-based observations are required for calibration of image datasets.

\section{Conclusions}

This study demonstrates the potential of a UAV, equipped with an innovative payload, to retrieve WSE and water depth observations in the wetlands and cenotes of the YP. In particular, this study showed that:

- UAV-borne WSE was retrieved with an accuracy better than 5-7 $\mathrm{cm}$ in a subset of the lagoons of the Yucatan Peninsula. These observations can be used to estimate groundwater streamlines and hydraulic gradients.

- Water depth was retrieved with an estimated accuracy of $\sim 3.8 \%$ of the actual water depth. Bathymetry observations were shown to be capable of identifying a fracture in the bed of a lagoon that creates a direct connection between the surface water and the underlying aquifer.

- In most jug-shaped cenotes on the YP, vegetation overhanging the water body disturbs the GNSS system and, concurrently, the narrow field of view to the water surface challenges the radar instrumentation. To solve these issues: i) GNSS and IMU data can be integrated with an ultra-tightly coupled solution in order to obtain accurate drone solution position when the GNSS signal quality is 
degraded by the disturbing surroundings; ii) accurate target selection with radar instrumentation also ensures measurements of water targets with small view of the sky.

- UAV data could serve as training data for satellite observations. Indeed, InSAR observations can only retrieve WSE changes in wetlands and require absolute WSE data to be calibrated and referenced to mean sea level. Similarly, optical satellite-derived bathymetry requires observations for calibration and validation of the water depth observations.

\section{Acknowledgements}

524 The Innovation Fund Denmark is acknowledged for providing funding for this study via the project Smart

525 UAV [125-2013-5]. Amigos de Sian Ka'an A.C is acknowledged for the hospitality and for the help during the

526 flight campaigns. Amigos de Sian Ka'an (http://www.amigosdesiankaan.org/es/) is one of the leading NGOs in

527 Mexico dedicated to environmental conservation and sustainable development of the YP. Without associations

528 such as Amigos de Sian Ka'an A.C, scientific research aimed to promote public policies and preserve the

529 biodiversity and the natural resources of the peninsula would not be possible. In particular, we thank its

530 “Mayan” co-workers Cornelio Baas and Sebastian Cach Chuc for the support and the valuable assistance

531 during the surveys. From Amigos de Sian Ka'an we also thank Liliana Garcia Ramírez for the support and the

532 help during the planning phase and organization process.

\section{Appendix A}

Figure 11 depicts UAV-borne water depth observations retrieved in Laguna Balam Nah, Pucté, cenote K’ux

536 Chúuk, and cenote Vigía Chico. 


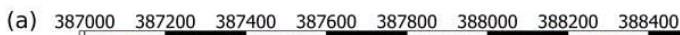

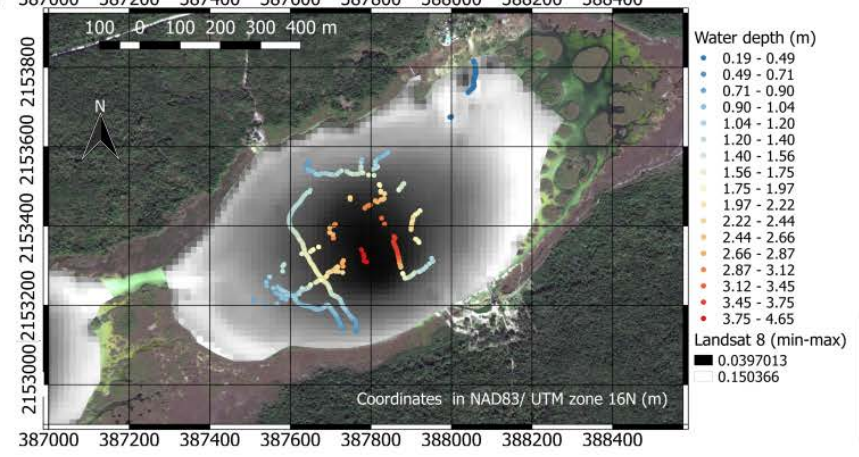

(b)

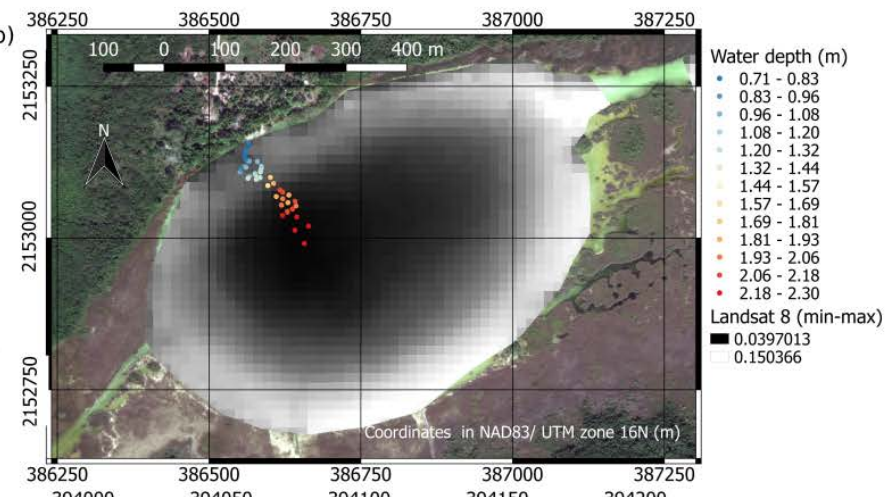

(c)

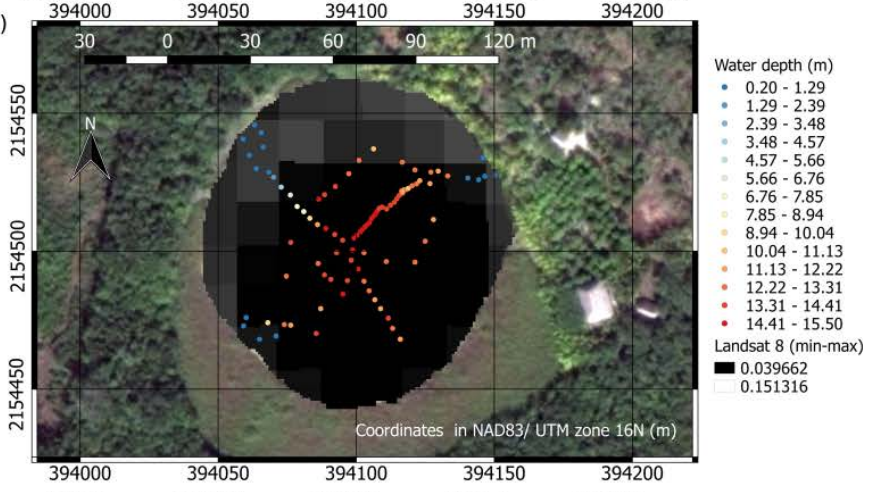

(d)

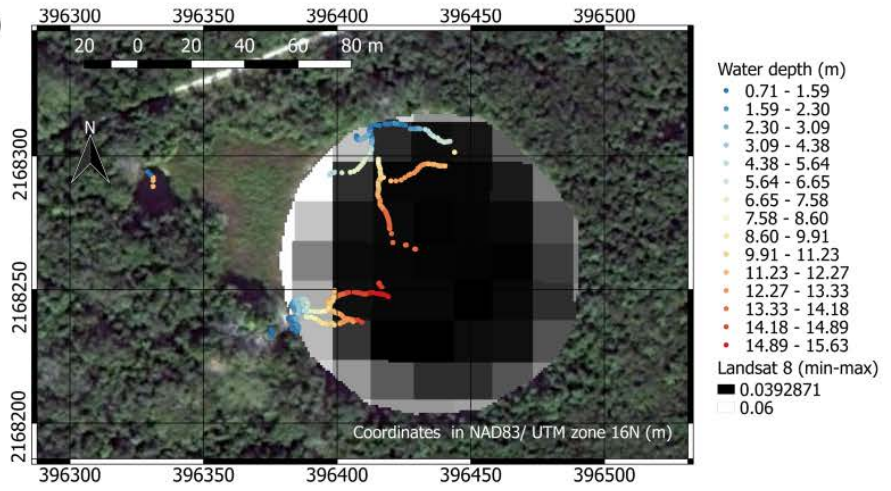

539 Fig. 11 Bathymetry observations in water body (a) laguna IV (Balam Nah), (b) laguna III (Pucté), (c) cenote

540 VII (K’ux Chúuk), and (d) cenote X (Vigía Chico). 


\section{References}

Alsdorf D, Melack J, Dunne T, et al (2000) Interferometric radar measurements of water level changes on the Amazon flood plain. Nature. 404(6774): 174-7, doi 10.1038/35004560

Alsdorf DE, Smith LC, Melack JM (2001) Amazon floodplain water level changes measured with interferometric SIR-C radar. IEEE Trans Geosci Remote Sens. 39(2): 423-431, doi 10.1109/36.905250

Amigos de Sian Ka’an, Colectividad Razonatura A.C. (2012) Censo de Cenotes de Quintana Roo (census of cenotes of Quintana Roo). http://www.amigosdesiankaan.org/es/proyectos/agua/54-logros-recientes. Accessed 15 Jun 2017

Asadzadeh Jarihani A, Callow JN, Johansen K, Gouweleeuw B (2013) Evaluation of multiple satellite altimetry data for studying inland water bodies and river floods. J Hydrol. 505: 78-90, doi 10.1016/j.jhydrol.2013.09.010

Bandini F, Jakobsen J, Olesen D, et al (2017a) Measuring water level in rivers and lakes from lightweight Unmanned Aerial Vehicles. J Hydrol. 548: 237-250, doi 10.1016/j.jhydrol.2017.02.038

Bandini F, Olesen D, Jakobsen J, et al (2017b) Bathymetry observations of inland water bodies using a tethered single-beam sonar controlled by an Unmanned Aerial Vehicle. Hydrol Earth Syst Sci Discuss. : Manuscript under review, doi https://doi.org/10.5194/hess-2017-625

Bauer-Gottwein P (2016) SmartUAV: New and innovative data collection platform and sensor technology DTU Environment. http://www.env.dtu.dk/english/Research_NEW/WRE_NEW/Project-SmartUAV. Accessed 23 Apr 2017

Bauer-Gottwein P, Gondwe BRN, Charvet G, et al (2011) Review: The Yucatan Peninsula karst aquifer, Mexico. Hydrogeol J. 19: 507-524, doi 10.1007/s10040-010-0699-5

Beddows P, Blanchon P (2007) Los cenotes de la península de Yucatán (The cenotes of the Yucatan Peninsula). In: Arquelogía Mex. http://www.seduma.yucatan.gob.mx/cenotesgrutas/documentos/cenotes-peninsula.pdf. Accessed 23 Apr 2017

Bergeron N, Carbonneau PE (2012) Geosalar: Innovative Remote Sensing Methods for Spatially Continuous 
Mapping of Fluvial Habitat at Riverscape Scale. In: Fluvial Remote Sensing for Science and Management. pp 193-213

Biancamaria S, Frappart F, Leleu AS, et al (2017) Satellite radar altimetry water elevations performance over a 200 m wide river: Evaluation over the Garonne River. Adv Sp Res. 59(1): 128-146, doi 10.1016/j.asr.2016.10.008

Calmant S, Seyler F, Cretaux JF (2008) Monitoring continental surface waters by satellite altimetry. Surv Geophys. 29(4-5): 247-269, doi 10.1007/s10712-008-9051-1

Carbonneau PE, Lane SN, Bergeron N (2006) Feature based image processing methods applied to bathymetric measurements from airborne remote sensing in fluvial environments. Earth Surf Process Landforms. 31(11): 1413-1423, doi 10.1002/esp.1341

Cerdeira-Estrada S, Heege T, Kolb M, et al (2012) Benthic habitat and bathymetry mapping of shallow waters in Puerto morelos reefs using remote sensing with a physics based data processing. In: 2012 IEEE International Geoscience and Remote Sensing Symposium. IEEE, pp 4383-4386

Chander G, Markham BL, Helder DL (2009) Summary of current radiometric calibration coefficients for Landsat MSS, TM, ETM+, and EO-1 ALI sensors. Remote Sens Environ. 113(5): 893-903, doi 10.1016/j.rse.2009.01.007

Connors M, Hildebrand AR, Pilkington M, et al (1996) Yucatan karst features and the size of Chicxulub crater. Geophys J Int. 127(3): F11-F14, doi 10.1111/j.1365-246X.1996.tb04066.x

Domeneghetti A, Castellarin A, Tarpanelli A, Moramarco T (2015) Investigating the uncertainty of satellite altimetry products for hydrodynamic modelling. Hydrol Process. 29(23): 4908-4918, doi 10.1002/hyp.10507

DTU, Sky-Watch (2017) Smart UAV-video. https://www.youtube.com/watch?v=No4zbFxnJFM. Accessed 24 May 2017

Escolero OA, Marin LE, Steinich B, Pacheco J (2000) Delimitation of a hydrogeological reserve for a city within a karstic aquifer: The Merida, Yucatan example. Landsc Urban Plan. 51(1): 53-62, doi 10.1016/S0169-2046(00)00096-7 
Eugenio F, Marcello J, Martin J (2015) High-Resolution Maps of Bathymetry and Benthic Habitats in ShallowWater Environments Using Multispectral Remote Sensing Imagery. Geosci Remote Sensing, IEEE Trans. 53(7): 3539-3549, doi 10.1109/TGRS.2014.2377300

Feurer D, Bailly J-S, Puech C, et al (2008) Very-high-resolution mapping of river-immersed topography by remote sensing. Prog Phys Geogr. 32(4): 403-419, doi 10.1177/0309133308096030

Flener C, Vaaja M, Jaakkola A, et al (2013) Seamless mapping of river channels at high resolution using mobile liDAR and UAV-photography. Remote Sens. 5(12): 6382-6407, doi 10.3390/rs5126382

Gondwe BRN, Hong SH, Wdowinski S, Bauer-Gottwein P (2010a) Hydrologic dynamics of the ground-waterdependent Sian Ka’an wetlands, Mexico, derived from InSAR and SAR data. Wetlands. 30(1): 1-13, doi 10.1007/s13157-009-0016-z

Gondwe BRN, Lerer S, Stisen S, et al (2010b) Hydrogeology of the south-eastern Yucatan Peninsula: New insights from water level measurements, geochemistry, geophysics and remote sensing. J Hydrol. 389: 117, doi 10.1016/j.jhydrol.2010.04.044

Google Earth (2017) SIO, NOAA, U.S. Navy, NGA, GEBCO. Image Landsat / Copernicus. 2017 INEGI. https://www.google.com/earth/. Accessed 26 Jun 2017

Gorelick N, Hancher M, Dixon M, et al (2016) Google Earth Engine: Planetary-scale geospatial analysis for everyone. Remote Sens Environ. doi: 10.1016/j.rse.2017.06.031

Groves P (2013) Principles of GNSS, Inertial, and Multisensor Integrated Navigation Systems. Artech House

Hall FG (1936) Physical and chemical survey of cenotes of Yucatan. Carnegie Inst. Wash. Publ.

Hildebrand AR, Penfield GT, Kring D a., et al (1991) Chicxulub Crater: A possible Cretaceous/Tertiary boundary impact crater on the Yucatán Peninsula, Mexico. Geology 19:867

Hildebrand AR, Pilkington M, Connors M, et al (1995) Size and Structure of the Chicxulub Crater Revealed by Horizontal Gravity Gradients and Cenotes. Nature. 376(6539): 415-417, doi http://dx.doi.org/10.1038/376415a0

INEGI 
620

621

Jagalingam P, Akshaya BJ, Hegde AV (2015) Bathymetry mapping using landsat 8 satellite imagery. In: Procedia Engineering. pp 560-566

Jerlov NG (1976) Marine Optics. Elsevier Science

Klemas V V. (2015) Coastal and Environmental Remote Sensing from Unmanned Aerial Vehicles: An Overview. J Coast Res. 315(5): 1260-1267, doi 10.2112/JCOASTRES-D-15-00005.1

Kløve B, Allan A, Bertrand G, et al (2011) Groundwater dependent ecosystems. Part II. Ecosystem services and management in Europe under risk of climate change and land use intensification. Environ Sci Policy. 14(7): 782-793, doi 10.1016/j.envsci.2011.04.005

Knudsen P, Linden-Vørnle M, Jakobsen J (2015) New drone combines helicopter and aircraft capabilities DTU. http://www.space.dtu.dk/english/news/Nyhed?id=98e9fed8-3b1f-49f1-ba54-7990ae6a625c. Accessed 25 Apr 2017

Lane SN, Widdison PE, Thomas RE, et al (2010) Quantification of braided river channel change using archival digital image analysis. Earth Surf Process Landforms. 35(8): 971-985, doi 10.1002/esp.2015

Legleiter CJ (2012) Remote measurement of river morphology via fusion of LiDAR topography and spectrally based bathymetry. Earth Surf Process Landforms. 37(5): 499-518, doi 10.1002/esp.2262

Legleiter CJ (2014) A geostatistical framework for quantifying the reach-scale spatial structure of river morphology: 2. Application to restored and natural channels. Geomorphology. 205: 85-101, doi 10.1016/j.geomorph.2012.01.017

Legleiter CJ, Roberts DA (2005) Effects of channel morphology and sensor spatial resolution on image-derived depth estimates. Remote Sens Environ. 95(2): 231-247, doi 10.1016/j.rse.2004.12.013

Legleiter CJ, Roberts DA, Lawrence RL (2009) Spectrally based remote sensing of river bathymetry. Earth Surf Process Landforms. 34(8): 1039-1059, doi 10.1002/esp.1787

Legleiter CJ, Roberts DA, Marcus WA, Fonstad MA (2004) Passive optical remote sensing of river channel morphology and in-stream habitat: Physical basis and feasibility. Remote Sens Environ. 93(4): 493-510, 
Lejot J, Delacourt C, Piégay H, et al (2007) Very high spatial resolution imagery for channel bathymetry and topography from an unmanned mapping controlled platform. Earth Surf Process Landforms. 32(11): 1705-1725, doi 10.1002/esp.1595

Lu Z, Crane M, Kwoun O-I, et al (2005) C-band radar observes water level change in swamp forests. Eos, Trans Am Geophys Union. 86(14): 141, doi 10.1029/2005EO140002

Lu Z, Kwoun OI (2008) Radarsat-1 and ERS InSAR analysis over southeastern coastal Louisiana: Implications for mapping water-level changes beneath swamp forests. IEEE Trans Geosci Remote Sens. 46(8): 21672184, doi 10.1109/TGRS.2008.917271

Lyzenga DR (1981) Remote sensing of bottom reflectance and water attenuation parameters in shallow water using aircraft and Landsat data. Int J Remote Sens. 2(1): 71-82, doi 10.1080/01431168108948342

Mandlburger G, Pfennigbauer M, Wieser M, et al (2016) Evaluation Of A Novel Uav-Borne Topo-Bathymetric Laser Profiler. ISPRS - Int Arch Photogramm Remote Sens Spat Inf Sci. XLI-B1: 933-939, doi 10.5194/isprs-archives-XLI-B1-933-2016

Marcus WA, Fonstad MA, Legleiter CJ (2012) Management Applications of Optical Remote Sensing in the Active River Channel. In: Fluvial Remote Sensing for Science and Management. John Wiley \& Sons, Ltd, Chichester, UK, pp 19-41

Marín LE (1990) Field investigations and numerical simulation of groundwater flow in the karstic aquifer of northwestern Yucatan, Mexico, PhD thesis. Northern Illinois University, DeKalb

Merediz-Alonso G (2007) Sustainable Management of Groundwater in Mexico. In: Holliday, L., Marin, L., Vaux H (ed) Proceedings of a Workshop (Series: Strengthening science-based decision making in developing countries). National Academies Press, Washington, D.C.

Mishra D, Narumalani S, Lawson M, Rundquist D (2004) Bathymetric Mapping Using IKONOS Multispectral Data. GIScience Remote Sens. 41(4): 301-321, doi 10.2747/1548-1603.41.4.301

Mohamed H, Negm A, Zahran M, Saavedra OC (2016) Bathymetry Determination from High Resolution Satellite Imagery Using Ensemble Learning Algorithms in Shallow Lakes: Case Study El-Burullus Lake. 
Navarro-Mendoza M (1988) Inventario íctico y estudios ecológicos preliminares en los cuerpos de agua

O’Loughlin FE, Neal J, Yamazaki D, Bates PD (2016) ICESat-derived inland water surface spot heights. Water Resour Res. 52(4): 3276-3284, doi 10.1002/2015WR018237

Ore JP, Elbaum S, Burgin A, Detweiler C (2015) Autonomous aerial water sampling. J F Robot. 32(8): 1095-

Olesen D, Jakobsen J, Knudsen P (2017) Ultra-Tightly Coupled GNSS/INS for Small UAVs. In: Proceedings of the 30th International Technical Meeting of The Satellite Division of the Institute of Navigation (ION GNSS+ 2017)

1113, doi 10.1002/rob.21591

Pacheco A, Horta J, Loureiro C, Ferreira (2015) Retrieval of nearshore bathymetry from Landsat 8 images: A tool for coastal monitoring in shallow waters. Remote Sens Environ. 159: 102-116, doi 10.1016/j.rse.2014.12.004

Perry E, Marin L, McClain J, Velazquez G (1995) Ring of Cenotes (sinkholes), northwest Yucatan, Mexico: its hydrogeologic characteristics and possible association with the Chicxulub impact crater. Geology 23:1720 

Hydrogeological Parameters Over the Coastal Karst System of Tulum, Mexico. In: Advances in Karst Science. Springer, Cham, pp 35-43

Schmitter-Soto JJ, Comín FA, Escobar-Briones E, et al (2002) Hydrogeochemical and biological characteristics of cenotes in the Yucatan Peninsula (SE Mexico). Hydrobiologia. 467: 215-228, doi 10.1023/A:1014923217206

Schumann GJ-P, Domeneghetti A (2016) Exploiting the proliferation of current and future satellite observations of rivers. Hydrol Process. 30(16): 2891-2896, doi 10.1002/hyp.10825

Sharpton V, Dalrymple G, Marín L (1992) New links between the Chicxulub impact structure and the Cretaceous/Tertiary boundary. Nature. 2(3): 173-179, doi 10.1038/359819a0

Sharpton VL, Burke K, Camargo-Zanoguera A, et al (1993) Chicxulub Multiring Impact Basin: Size and Other Characteristics Derived from Gravity Analysis. Science (80- ). 261(5128): 1564-1567, doi 10.1126/science.261.5128.1564

Stumpf RP, Holderied K, Sinclair M (2003) Determination of water depth with high-resolution satellite imagery over variable bottom types. Limnol Oceanogr. 48(1part2): 547-556, doi 10.4319/lo.2003.48.1_part_2.0547

Tauro F, Porfiri M, Grimaldi S (2016) Surface flow measurements from drones. J Hydrol. 540: 240-245, doi 10.1016/j.jhydrol.2016.06.012

Villadsen H, Andersen OB, Stenseng L, et al (2015) CryoSat-2 altimetry for river level monitoring Evaluation in the Ganges-Brahmaputra River basin. Remote Sens Environ. 168: 80-89, doi 10.1016/j.rse.2015.05.025

Westaway RM, Lane SN, Hicks DM (2000) The development of an automated correction procedure for digital photogrammetry for the study of wide, shallow, gravel-bed rivers. Earth Surf Process Landforms. 25(2): 209-226, doi 10.1002/(SICI)1096-9837(200002)25:2<209::AID-ESP84>3.0.CO;2-Z

Westaway RM, Lane SN, Hicks DM (2001) Remote sensing of clear-water, shallow, gravel-bed rivers using digital photogrammetry. Photogramm Eng Remote Sensing. 67(11): 1271-1281,

Winterbottom SJ, Gilvear DJ (1997) Quantification of channel bed morphology in gravel-bed rivers using 

airborne multispectral imagery and aerial photography. Regul Rivers-Research Manag. 13(6): 489-499, doi 10.1002/(SICI)1099-1646(199711/12)13:6<489::AID-RRR471>3.0.CO;2-X

724
Woodget AS, Carbonneau PE, Visser F, Maddock IP (2015) Quantifying submerged fluvial topography using hyperspatial resolution UAS imagery and structure from motion photogrammetry. Earth Surf Process Landforms. 40(1): 47-64, doi 10.1002/esp.3613 